\title{
A novel bandwidth enhanced triple band antenna for satellite and airborne applications
}

\author{
Mohammed Ismail Mohammed \\ Ethiopian Institute of Technology, Mekelle University, Ethiopia
}

\begin{tabular}{l}
\hline \hline Article Info \\
\hline Article history: \\
Received Nov 9, 2019 \\
Revised Jan 14, 2020 \\
Accepted Jan 28, 2020 \\
\hline
\end{tabular}

\section{Keywords:}

Enhanced bandwidth

Miniaturization

Parasitic coupling

Parasitic stack

Sierpinski carpet

\begin{abstract}
This paper presents a novel bandwidth enhancement technique in which a passive stack of third order Sierpinski carpet fractal antenna is parasitically coupled to the driven element that is also a Sierpinski fractal of third order. Edge feeding technique is used. The passive stack placed symmetric to the driven elements provide the combined benefits of horizontal and vertical parasitic coupling, with added advantage of miniaturization contributed by fractal technology. Result of the study indicate that the antenna array provide triple band with a large inter-band separation that mitigates the effects of inter-band interference. The first band at $6.1 \mathrm{Ghz}$ with bandwidth of $250 \mathrm{Mhz}$ supports mobile wireless and fixed satellite service, the second band at 7.1 Ghz with 350Mhz bandwidth supports mobile wireless, fixed wireless and fixed satellite service. The third band is at $11.6 \mathrm{Ghz}$ with bandwidth of $1.4 \mathrm{Ghz}$ and supports fixed wireless and fixed satellite services. The number of elements in the parasitic stack influence array performance in terms of bandwidth, gain and directivity. The bandwidth in the third band increased from $1.5 \mathrm{Ghz}$ for two-element stack to $1.7 \mathrm{Ghz}$ for three-element. This has an advantage over conventional antenna array, that use more active antenna elements that have the limitations of more power consumption and large space occupancy.
\end{abstract}

Copyright $(9) 2020$ Institute of Advanced Engineering and Science. All rights reserved.

\section{Corresponding Author:}

Mohammed Ismail Mohammed, Ethiopian Institute of Technology, Mekelle University, P. Box.231, Mekelle, Ethiopia.

Email: ermohammedib@gmail.com

\section{INTRODUCTION}

The lower portion of the frequency spectrum is almost saturated, and the emerging wireless technologies demand antenna array that exhibit large bandwidth with a wide inter-band separation to mitigate adjacent channel interference. Also, the antenna array must support multiband operation and be miniaturized in terms of size and weight, that is highly desirable in satellite and air-borne applications [1]. Researchers have used different antenna technologies to achieve wide-band and multiband operations. Bandwidth enhancement can also be achieved by using microstrip antenna array with air as substrate. In [2], patch antenna has been designed with air substrate, but the bandwidth enhancement is not significant. Another bandwidth enhancement technique is the use of slots. In [3], attempts to apply an adaptive networkbased fuzzy inference system (ANFIS) for analysis of the resonant frequency of a microstrip patch antenna with two equal size slots placed on the patch in the form of parallel to resonance edges is proposed. The bandwidth is good, but exhibits poor gain and directivity. In [4], design of a T and L slotted microstrip patch antenna for future mobile and wireless communication is proposed. The antenna has good bandwidth improvement, again with poor gain and directivity. In [5], bandwidth enhancement technique by using T-shaped slot operating at $2.4 \mathrm{Ghz}$ using proximity coupled feeding is presented. The proposed antenna operates at $2.4 \mathrm{Ghz}$ and $4.5 \mathrm{Ghz}$ supporting $\mathrm{C}$-band and satellite applications. The gain and directivity improvement is not significant. 
Bandwidth can also be enhanced by using annular rings. In [6], a new design for the annular ring microstrip antenna that utilizes two shorting pins to reduce the antenna to $25 \%$ of its original size by decreasing the resonant frequency is proposed. The antenna exhibits omnidirectional pattern and is vertically polarized. In [7] a dual band annular ring patch antenna is investigated using the equivalent circuit concept. Two symmetrical rectangular notches are etched in radiating ring patch with respect to feed point. It is observed that the resonant frequency is directly proportional to the notch width and notch length. The bandwidth of the antenna at lower and higher ends are $134 \mathrm{MHz}(1.815-1.681 \mathrm{GHz})$ and $212 \mathrm{MHz}$ (2.849-2.637GHz).

Another bandwidth enhancement that has gained prominence is the gap coupled technique. In this technique, only one driven element is parasitically coupled to other elements which act as parasitic elements. This technique provides better gain and directivity but the bandwidth obtained is not significant. However, there is sufficient inter-band seperation that mitigates adjacent band interference [8-10]. Another antenna technology towards bandwidth enhancement is horizontal parasitic coupling. The procedures use the concept that if the resonant frequency of the coupled element or elements is slightly different to that of driven patch, then the overall bandwidth of the antenna could be enhanced. Bandwidths in the order of $20 \%$ have been achieved using this enhancement technique. This method, however have the limitation of occupying more space, and the improvement in antenna characteristics by using more parasitic elements add to the grating lobe problem [11]. By using additional microstrip patches directly coupled to the radiating or non-radiating edges of a rectangular microstrip antenna, broadband microstrip antenna can be designed. However, the limitation of this is the increased antenna size [12].

To mitigate the problem of more space occupancy by the horizontal parasitic coupling, another technology for bandwidth enhancement is stacking. A stacked microstrip antenna with H-shaped parasitic patch for multiband applications is presented in [13]. The antenna exhibits multiband and wideband operation, but has low gain and directivity. In [14], a dual band stacked micostrip antenna array is presented for wireless local area network. Stacking of the patches is done to achieve dual band and resonant slot to achieve greater bandwidth. The antenna shows a bandwidth of $228.3 \mathrm{MHz}$ from 3.63 to $3.86 \mathrm{GHz}$ and 232 $\mathrm{MHz}$ from 5.15 to $5.38 \mathrm{GHz}$. To obtain large bandwidth at the same time obtain miniaturization, fractal and stack technology is integrated. In [15], a novel design of a stacked two layer microstrip patch antenna with wideband characteristics is proposed. The impedance bandwidth of single layer patch is $7 \%$. After using stacking and fractal methodology, the impedance bandwidth increases up to $69 \%$ ranging from $7.5 \mathrm{GHz}$ to $14.4 \mathrm{GHz}$ with acceptable return loss. In [16], the design and analysis of a triangular shape inverted fractal patch antenna is proposed and shows miniaturization and multiband operation without degradation of its gain. It is found that second iterated structure resonates at $2.3367 \mathrm{GHz}, 5.39 \mathrm{GHz}, 7.58 \mathrm{GHz}$ with corresponding gain $8.68 \mathrm{~dB}, 7.30 \mathrm{~dB}$ and $6.33 \mathrm{~dB}$. In [17], an antenna array is formed using Giuseppe Peano fractal patches for achieving both wideband and high gain properties is proposed. The simulation and measurment results contribute to wideband, high directivity and high aperture efficiency. However, the interband seperation is not significant. A dual frequency broadband microstrip antenna with a reactive loading and stacked elements is proposed in [18]. The results exhibit enhanced bandwidth and gain with some betterment in inter-band seperation.

From the literature review, we see that, using a single patch with different techniques such as air substrate, slot loading, integrated reactive loading and annular ring provide a bandwidth improvement of about $8 \%$, which is not adequate for wireless systems. Using multiple antenna elements could be one solution of bandwidth enhancement. Using horizontal parasitic coupled antenna does provide a bandwidth improvement of about $20 \%$ which is good enough, but they occupy more space [19]. Bandwidth enhancement is also achieved by parasitic gap coupling of identical antenna. Here a single rectangular microstrip patch is split into equal smaller elements along the width, keeping the length same. Of these, one of the elements is fed while others are gap coupled to its non-radiating edges [20]. Stacked antenna provide good bandwidth enhancement, but not good gain and directivity.

The novelty of the proposed work is that there is a single third order Sierpinski carpet driven element that horizontally couples the stack of passive elements placed symmetrically to the driven element. The elements in the stack are also Sierpinski carpet of third order. Inset feeding technique is used. The parasitic elements in the stack are increased gradually, and its influence on bandwidth enhancement and improvement in radiation characteristics in the form of gain, directivity and radiation efficiency is investigated. 


\section{RESEARCH METHOD}

\subsection{Design of patch antenna}

A rectangular patch antenna is designed to operate at $3.5 \mathrm{Ghz}$ by using Rogers RT /duroid 5880(tm) dielectric material with a dielectric constant of 2.2. The dielectric constant of the substrate $\varepsilon_{\mathrm{r}}$ is typically in the range of $2 \ll \varepsilon_{\mathrm{r}} \ll 12$ [21]. When it comes to dielectric material choice, a material with lower value of dielectric constant, by default represents a thick dielectric material, and a thick dielectric material facilitate bandwidth enhancement. Using the expression for the limiting value for the height of the substrate, defined by, $0.003 \lambda_{0} \leq \mathrm{h} \leq 0.05 \lambda_{0}$, and using the dielectric material manufacturer data sheet,the selected height of the dielectric substrate is $1.575 \mathrm{~mm}$. Using the resonant frequency,relative permittivity and thickness of the substrate, the dimensions of the patch, ground plane and feed are determined. This is presented in the following section:

\subsubsection{Dimension of the patch}

Rectangular patch antenna width (w):

$\mathrm{W}=\frac{\mathrm{c}}{2 \mathrm{f} \sqrt{[\varepsilon r+1] / 2}}$

$\mathrm{W}=\frac{3 * 10^{8}}{2\left[2.4 * 10^{9}\right] \sqrt{[2.2+1] / 2}}$

$\mathrm{w}=33.9 \mathrm{~mm}$

Effective dielectric constant of substrate $\left(\varepsilon_{\text {reff }}\right)$ :

$\varepsilon_{\text {reff }}=\frac{\varepsilon_{\mathrm{r}}+1}{2}+\frac{\varepsilon_{\mathrm{r}}-1}{2}\left(1+12 \frac{\mathrm{h}}{\mathrm{w}}\right)^{\frac{-1}{2}}$

$\varepsilon_{\text {reff }}=\frac{2.2+1}{2}+\frac{2.2-1}{2}\left(1+12 \frac{1.575 * 10^{-3}}{33.9 * 10^{-3}}\right)^{\frac{-1}{2}}$

$\varepsilon_{\text {reff }}=2.286$

Effective electrical length of the patch $\left(L_{e f f}\right)$ :

$\mathrm{L}_{\text {eff }}=\frac{\mathrm{c}_{\mathrm{o}}}{2 \mathrm{f} \sqrt{\varepsilon_{\mathrm{r}}}}$

$\mathrm{L}_{\mathrm{eff}}=3 * 10^{8} /\left(2\left[3.5 * 10^{9}\right] \sqrt{ }(2.2)\right)$

$\mathrm{L}_{\text {eff }}=30.30 \mathrm{~mm}$

The extended length of the patch $(\Delta \mathrm{L})$ :

$\Delta \mathrm{L}=0.412 \mathrm{~h} \frac{\left(\varepsilon_{\text {reff }+0.3)}\left(\frac{\mathrm{W}}{\mathrm{h}}+0.264\right)\right.}{\left(\varepsilon_{\text {reff-0.258) }}\left(\frac{\mathrm{W}}{\mathrm{h}}+0.8\right)\right.}$

$\Delta \mathrm{L}=0.412\left(1.575 * 10^{-3}\right) \frac{(2.286+0.3)\left(\frac{33.9 * 10^{-3}}{1.575 * 10^{-3}}+0.264\right)}{(2.286-0.258)\left(\frac{33.9 * 10^{-3}}{1.575 * 10^{-3}}+0.8\right)}$

$\Delta \mathrm{L}=0.807 \mathrm{~mm}$

The length of the patch (L):

$\mathrm{L}=\mathrm{Leff}-2 \Delta \mathrm{L}$

$\mathrm{L}=30.30-2(0.8)=28.7 \mathrm{~mm}$ 


\subsubsection{Dimension of the feed}

Length of feed $\left(\mathrm{L}_{\mathrm{f}}\right)$ :

$$
\mathrm{L}_{\mathrm{f}}=\frac{85.71 * 10^{-3}}{4 \sqrt{2.2}}=14.44 \mathrm{~mm}
$$

Width of feed is given by:

$$
\begin{aligned}
& \mathrm{Z}_{0}=\frac{120 \pi}{\sqrt{\varepsilon_{\text {reff }}}\left(1.393+\frac{\mathrm{W}}{\mathrm{h}}+\frac{2}{3} \ln \left(\frac{\mathrm{W}}{\mathrm{h}}+1.444\right)\right)} \\
& 50 \Omega=\frac{120 \pi}{\sqrt{2.286}\left(1.393+\frac{\mathrm{W}}{1.575 \times 10^{-3}}+\frac{2}{3} \ln \left(\frac{\mathrm{W}}{1.575 \times 10^{-3}}+1.444\right)\right)}
\end{aligned}
$$

$\mathrm{W}=4.42 \mathrm{~mm}$

\subsubsection{Dimension of the ground plane}

Dimension of ground plane width $\left(\mathrm{W}_{\mathrm{g}}\right)$ and length $\left(\mathrm{L}_{\mathrm{g}}\right)$ :

Ground plane width $\left(\mathrm{W}_{\mathrm{g}}\right)=\mathrm{W}_{\mathrm{g}} 2 \mathrm{~L}_{\mathrm{f}}+\mathrm{W}$.

$\mathrm{Wg}=2(14.4 \mathrm{~mm})+33.9 \mathrm{~mm}=62.7 \mathrm{~mm}$

Ground plane length $\left(\mathrm{L}_{\mathrm{g}}\right)=2 \mathrm{~L}_{\mathrm{f}}+\mathrm{L}$

$\operatorname{Lg}=2(14.4 \mathrm{~mm})+28.7=57.5 \mathrm{~mm}$

The simulation parameters are listed in Table 1.

Table 1. Simulation parameters

\begin{tabular}{cc}
\hline Simulation Parameter & Value of parameter \\
\hline Resonant Frequency & $3.5 \mathrm{Ghz}$ \\
Dielectric substrate & Rogers RT Duroid/5880 \\
Relative Permittivity & 2.2 \\
Height of substrate & $1.575 \mathrm{~mm}$ \\
Patch width & $33.9 \mathrm{~mm}$ \\
Patch length & $28.7 \mathrm{~mm}$ \\
Length of feed & 14.44 \\
Width of feed & $4.42 \mathrm{~mm}$ \\
Width of ground plane & $62.7 \mathrm{~mm}$ \\
Length of ground plane & $57.5 \mathrm{~mm}$ \\
\hline
\end{tabular}

\subsection{Design of sierpinski carpet fractal antenna}

When we apply the concept of fractals to design antennas, a fractal can fill the space occupied by the antenna in a more effective manner than the traditional Euclidean antenna. This leads to more effective coupling of energy from feeding transmission lines to free space in less volume. These space-filling properties lead to curves that are electrically very long, but fit into a small physical space. This property can lead to the miniaturization of antenna elements [22-25]. The fractal-dimension is defined as a measure of the space-filling properties and complexity of the fractal shape. Fractal dimension is similar to Euclidean dimension, with the dimension of a line is 1 , planer surface is 2 , and box is 3 . The fractal dimension is always in the range of $1<\mathrm{D}<2$ and it depends on the fractal type. For example, the dimension of Sierpinski is not the same as Koch fractal. To determine the fractal dimension, one can simply use the power law relation between the number of pieces, a and the reduction factor, $s$ [26], defined in (10).

$$
\mathrm{a}=\frac{1}{\mathrm{~s}^{\mathrm{D}}}
$$

taking logarithms on both sides for, we get 


$$
\log \mathrm{a}=-\mathrm{D} * \log \mathrm{s}
$$

Equivalently,

$$
\mathrm{D}=-\frac{\log \mathrm{a}}{\log \mathrm{s}}
$$

Where $\mathrm{D}$ is, $1<\mathrm{D}<2$,

\subsubsection{Iterated Function Systems (IFS)}

An iterated function system is a method or algorithm to generate different fractals types. This algorithm uses an affine transformation [27] given in (12),

$$
W\left(\begin{array}{l}
x \\
y
\end{array}\right)=\left(\begin{array}{ll}
a & b \\
c & d
\end{array}\right)\left(\begin{array}{l}
x \\
y
\end{array}\right)+\left(\begin{array}{l}
e \\
f
\end{array}\right)
$$

where the parameters $a, b, c$ and $d$ are real numbers and define the rotation and scaling coefficient of initial geometry, and e and $\mathrm{f}$ define the translation variables.

This can be written more clearly as [28] in (13),

$$
\mathrm{W}\left[\begin{array}{l}
\mathrm{X} \\
\mathrm{y}
\end{array}\right]=\left[\begin{array}{cc}
\frac{1}{\mathrm{r}} \cos (\theta) & -\frac{1}{\mathrm{~s}} \sin (\theta) \\
\frac{1}{\mathrm{r}} \sin (\theta) & \frac{1}{\mathrm{~s}} \cos (\theta)
\end{array}\right]\left[\begin{array}{l}
\mathrm{x} \\
\mathrm{y}
\end{array}\right]+\left[\begin{array}{l}
\mathrm{e} \\
\mathrm{f}
\end{array}\right]
$$

This may be rearranged as given in (14),

$$
\mathrm{W}(\mathrm{x}, \mathrm{y})=\left(\frac{1}{\mathrm{r}} \cos (\theta) * \mathrm{x}-\frac{1}{\mathrm{~s}} \sin (\theta) * \mathrm{y}+\mathrm{e}, \frac{1}{\mathrm{r}} \sin (\theta) * \mathrm{x}+\frac{1}{\mathrm{~s}} \cos (\theta) * \mathrm{y}+\mathrm{f}\right)
$$

Where $\mathrm{r}$ and $\mathrm{s}$ are the scaling factors in $\mathrm{x}-$ and $\mathrm{y}-$ axis respectively, while $\theta$ defines the rotation angles in $\mathrm{x}-\mathrm{y}$ plane, and the variables, $\mathrm{e}$ and $\mathrm{f}$ define the translation variables.If we assume $\mathrm{n}$ number of sets of affine transformation, i.e $w_{n}, n=1,2,3, \ldots N$, and if we have $A$ to be an initial image, applying this set of transformations on the image generates a set of self-affine copies given in (15).

$$
W(A)=w_{1}(A) \cup w_{2}(A) \ldots \cup w_{N}(A)
$$

where, $\mathrm{W}$ is known as the Hutchinson operator.

The IFS is very important method to design fractal antennas for different applications. The construction of Sierpinski carpet is similar to the construction of Sierpinski gasket but instead of triangle, a square is used as a starting geometry. The square is subdivided into 9 congruent squares and the middle square is removed for first iteration. This construction method continues until the desired third iteration for the proposed study is obtained. The evolution stages for Sierpinski carpet is shown in Figure 1.
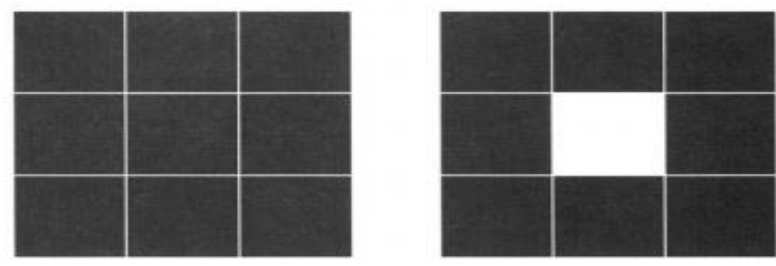

Figure 1. Evolutionary steps of the Sierpinski carpet [22]

\section{RESULT AND ANALYSIS}

The patch antenna designed to operate at $3.5 \mathrm{Ghz}$ is subjected to third order Sierpinski carpet fractal technology. Two parasitic elements are placed symmetrical to the driven element, and the performance of the parasitic coupled array is evaluated using return loss, voltage standing wave ratio(VSWR), impedance bandwidth, gain and directivity, and antenna efficiency. Next, a stack of two parasitic elements is designed, 
and placed symmetrical to the driven element and the performance evaluated. The same procedure is repeated for the stack with three parasitic elements. Finally, the influence of the number of parasitic elements in the stack on antenna performance is evaluated. This is discussed in the following section.

\subsection{Driven element parasitic coupled to symmetric parasitic elements}

The third order Sierpinski carpet fractal is used as the driven element using inset feeding technique, and two Sierpinski fractal of third order are placed symmetric to the driven element and coupled parasitically. The distance of separation between driven and parasitic element is kept at half wavelength to minimize mutual coupling effects. This arrangement is shown in Figure 2. Performance of the parasitic array is evaluated using the following metrics.

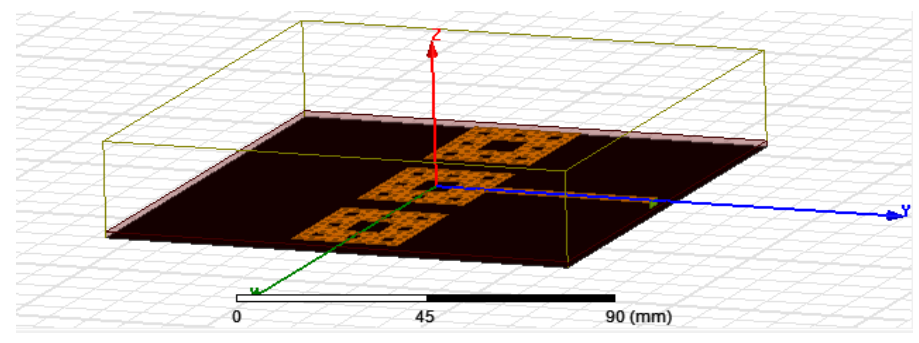

Figure 2. Driven element parasitic coupled to Symmetric Parasitic elements

Return loss [29]: - Return loss parameters reflects the matching condition attained and it helps us to evaluate the impedance bandwidth. This is shown in Figure 3. It is clear that the antenna operates at three bands of $6 \mathrm{GHz}$, with impedance band width of $250 \mathrm{MHz}, 7.1 \mathrm{GHz}$ with impedance bandwidth of $350 \mathrm{MHz}$ and $11.6 \mathrm{GHz}$ with impedance band width of $1.4 \mathrm{GHz}$. The corresponding return loss are $-14.81 \mathrm{~dB},-14.57$ $\mathrm{dB}$ and $-17.69 \mathrm{~dB}$ at $6 \mathrm{Ghz}, 7.1 \mathrm{Ghz}$ and $11.6 \mathrm{Ghz}$ respectively.

VSWR: - The theoretical limiting value of VSWR is 1 to 2 for a good antenna design. The VSWR for the designed antenna is 1.4 for $6 \mathrm{GHz}$ band, 1.45 for $7.1 \mathrm{GHz}$ band and 1.29 for $11.6 \mathrm{GHz}$ band which reflects that the proposed antenna design is optimal. This is shown in Figure 4.

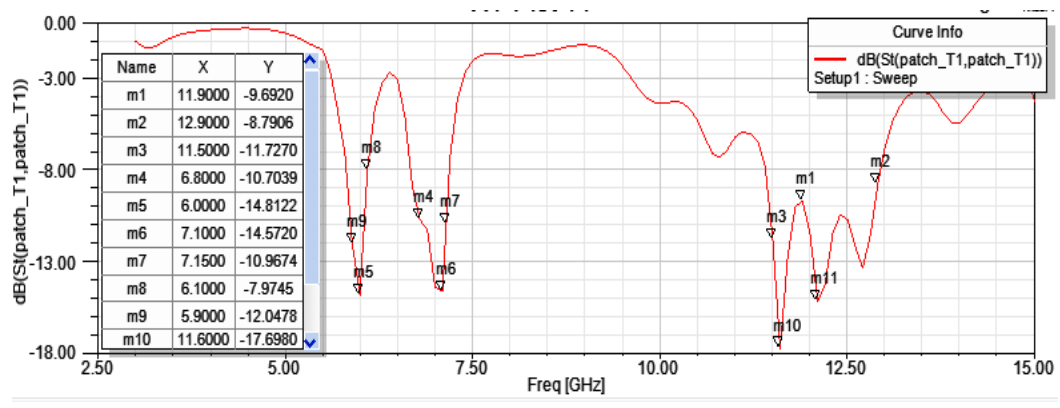

Figure 3. Return loss plot for Figure 2

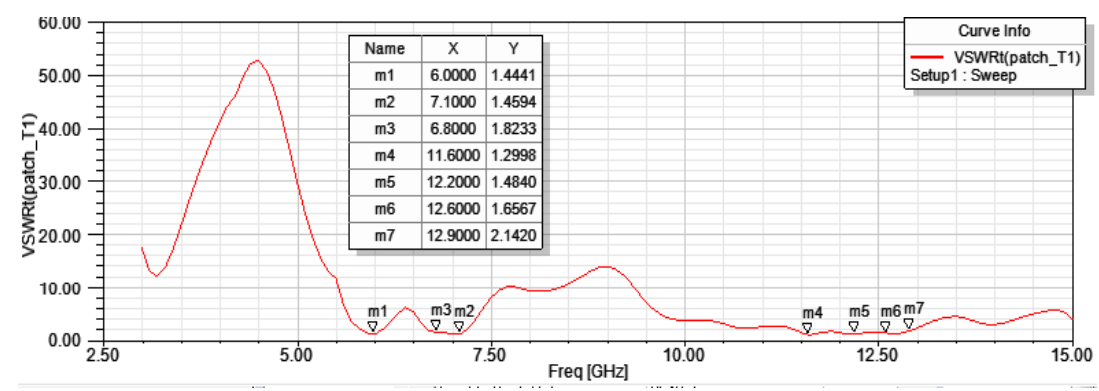

Figure 4. VSWR of Figure 2 


\section{Directivity, gain and radiation efficiency}

The proposed antenna shown in Figure 2 exhibits peak directivity of 7.97, peak gain of 7.4 which is well beyond an isolated fractal antenna. The results are tabulated in Table 2. The designed antenna exhibits an antenna efficiency of $93 \%$ which is good enough for majority of wireless applications. This is shown in Table 2.

Table 2. Peak gain, directivity and radiation efficiency of Figure 2

\begin{tabular}{|c|c|c|}
\hline Quantity & Value & Units \\
\hline $\operatorname{MaxU}$ & 0.0010081 & $\mathrm{~W} / \mathrm{sr}$ \\
\hline Peak Directivity & 7.9798 & \\
\hline Peak Gain & 7.4652 & \\
\hline Peak Realized Gain & 1.2669 & \\
\hline Radiated Power & 0.0015876 & w \\
\hline Accepted Power & 0.001697 & w \\
\hline Incident Power & 0.01 & w \\
\hline Radiation Efficiency & 0.93551 & \\
\hline Front to Back Ratio & 2548.7 & \\
\hline Decay Factor & 0 & \\
\hline
\end{tabular}

\subsection{Driven element parasitic coupled to a symmetric parasitic stack of two element}

A two element stack of parasitic elements is placed symmetrically to the driven element half lambda apart and this arrangement is shown in Figure 5. The distance of separation between the two parasitic elements in the stack is $3 \mathrm{~mm}$, and air is the dielectric material used. The influence of symmetric two elements parasitic stack on antenna performance is evaluated using the following metrics.

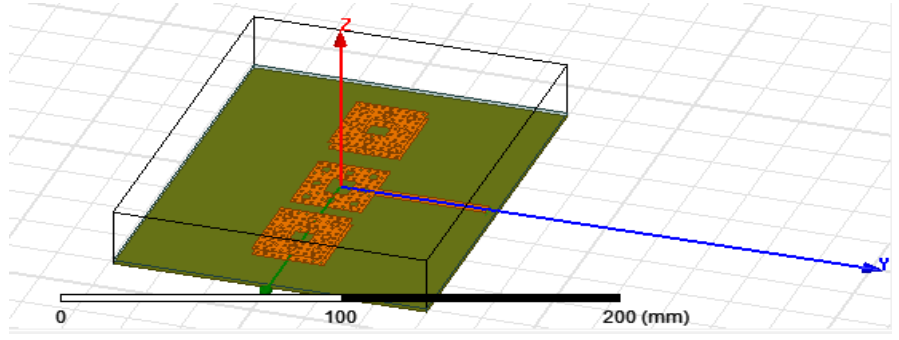

Figure 5. Driven element parasitic coupled to two-element symmetric parasitic stack

\section{Return loss}

Figure 6 shows that by placing two elements parasitic stack symmetrical to driven element, the operating bands remain unchanged at $6 \mathrm{GHz}, 7.1 \mathrm{GHz}$ and $11.6 \mathrm{GHz}$ compared to single parasitic element symmetrically placed to driven element shown in Figure 2. However, for the third band at $11.6 \mathrm{GHz}$, the impedance bandwidth improved to $1.5 \mathrm{GHz}$, from $1.4 \mathrm{Ghz}$ in single parasitic element placed symmetrical to driven element shown in Figure 2. A significant 1000Mhz bandwidth is obtained in the third band.

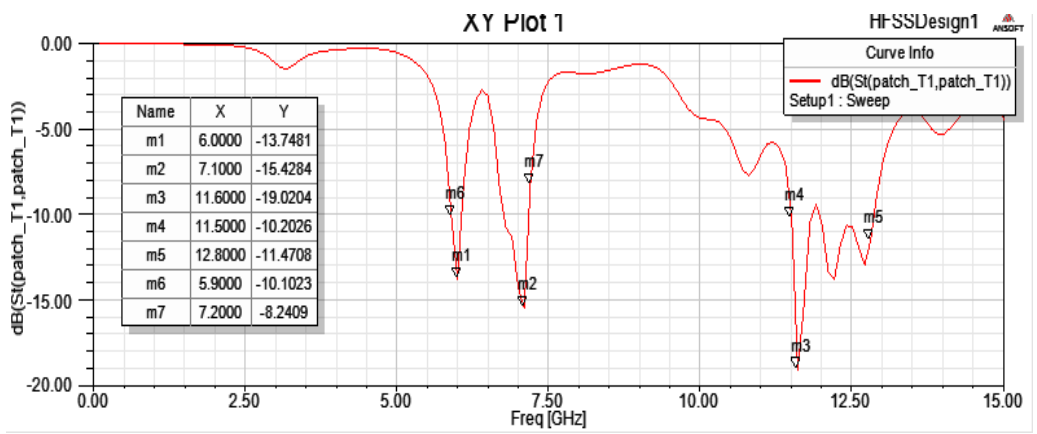

Figure 6. Return loss for Figure 5 
Peak directivity, peak gain and antenna efficiency

The directivity and peak gain for two parasitic element stack placed symmetrical to driven element shown in Figure 5, is $8.4 \mathrm{~dB}$ and $7.8 \mathrm{~dB}$ respectively. This means the directivity is improved by $0.43 \mathrm{~dB}(8.4-$ $7.97=0.43)$ and and gain is $0.4 \mathrm{~dB}(7.8-7.4=0.4)$ compared to single symmetric parasitic element coupled to driven element. The radiation efficiency however remains unchanged at $92.8 \%$. The results are tabulated in Table 3.

Table 3. Peak directivity, gain and antenna efficiency for Figure 5

\begin{tabular}{|c|c|c|c|}
\hline \multicolumn{4}{|c|}{ Antenna Parameters: } \\
\hline & Quantity & Value & Units \\
\hline & Max U & 0.0010561 & $\mathrm{~W} / \mathrm{sr}$ \\
\hline & Peak Directivity & 8.4282 & \\
\hline & Peak Gain & 7.8246 & \\
\hline & Peak Realized Gain & 1.3272 & \\
\hline & Radiated Power & 0.0015747 & w \\
\hline & Accepted Power & 0.0016962 & w \\
\hline & Incident Power & 0.01 & $w$ \\
\hline & Radiation Efficiency & 0.92838 & \\
\hline & Front to Back Ratio & 734.98 & \\
\hline & Decay Factor & 0 & \\
\hline
\end{tabular}

\subsection{Driven element parasitic coupled to symmetric three-element parasitic stack}

A three element parasitic stack is placed symmetrically to the driven element half lambda apart and this arrangement is shown in Figure 7. The distance of separation between the driven element and the parasitic stack is half lambda apart. This mitigates the mutual coupling effects to a certain extent. However, the distance of separation between the first and second parasitic elements is $3 \mathrm{~mm}$, and the distance of separation between second and third element is also $3 \mathrm{~mm}$. The space between the parasitic elements is filled with air as dielectric. The additional parasitic element on to the parasitic stack improves the performance of the antenna, and this is presented in the following section. The performance is evaluated using the following metrics.

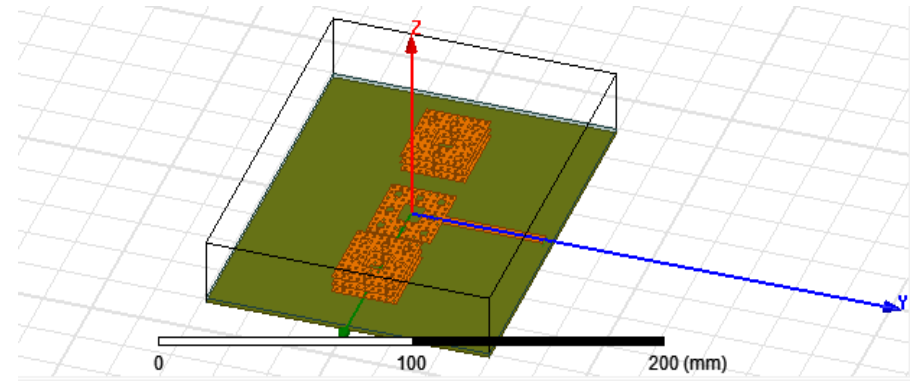

Figure 7. Driven element parasitic coupled to three-element symmetric parasitic stack

\section{Return loss}

The return loss plot shown in Figure 8 indicate that by adding one additional element to the parasitic stack, i.e from initial two-element stack to three element stack placed symmetrical to the driven element, the operating bands are reduced to two, from the earlier three bands in two elements parasitic stack. The first band is at $6 \mathrm{GHz}$ with an impedance bandwidth of $300 \mathrm{MHz}$ and return loss of $-13.74 \mathrm{~dB}$, and the second band is at $11.6 \mathrm{GHz}$ with an impedance bandwidth of $1.7 \mathrm{GHz}$, with a corresponding return loss of $-18.70 \mathrm{~dB}$. The second band at 11.6 Ghz provides a bandwidth improvement of $1.7-1.5=0.2 \mathrm{GHz}$ compared to the corresponding second band for two elements parasitic stack discussed in section3.2. 


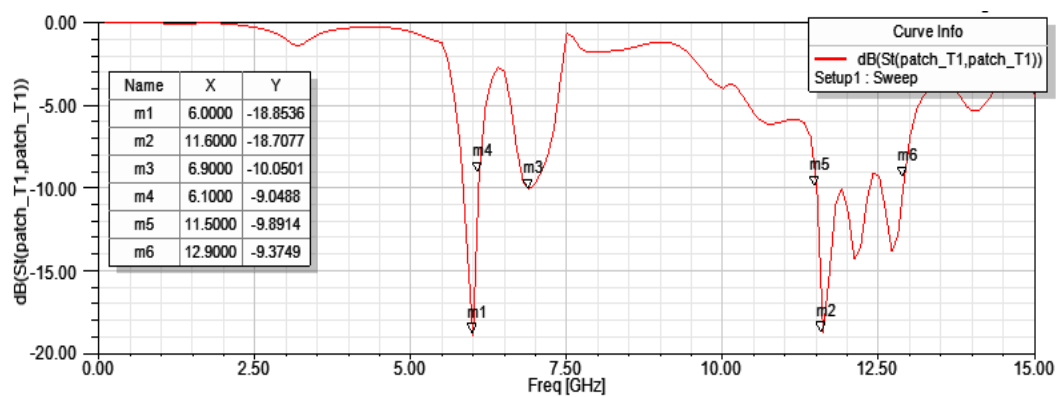

Figure 8. Return loss for Figure 7

\section{Peak directivity, Gain and antenna efficiency}

The three element parasitic stack horizontal coupled to driven element provides a directivity of $9.02 \mathrm{~dB}$ which is improved by $0.62 \mathrm{~dB}(9.02 \mathrm{~dB}-8.40 \mathrm{~dB}=0.62 \mathrm{~dB})$ compared to two elements parasitic stack. Also, the gain of $8.38 \mathrm{~dB}$ which is up by $0.58 \mathrm{~dB}(8.38-7.8=0.58)$. The peak directivity improves by $1.62 \mathrm{~dB}$ $(9.02 \mathrm{~dB}-7.4 \mathrm{~dB}=1.62 \mathrm{~dB})$ and gain by $0.98 \mathrm{~dB}(8.38 \mathrm{~dB}-7.4 \mathrm{~dB}=0.98 \mathrm{~dB})$ compared to a single parasitic element coupled horizontally to driven element. These results are projected from Tables 2, 3 and 4. The antenna Efficiency remains at $92.92 \%$ shown in Table 4.

Table 4. Directivity, gain and antenna efficiency for Figure 7

\begin{tabular}{l|l|l|l|} 
Antenna Parameters: & \multicolumn{2}{c|}{ Value } & Units \\
\hline & Max U & 0.0011598 & W/sr \\
\hline & Peak Directivity & 9.0266 & \\
\hline & Peak Gain & 8.3875 & \\
\hline & Peak Realized Gain & 1.4575 & \\
\hline & Radiated Power & 0.0016147 & W \\
\hline & Accepted Power & 0.0017377 & W \\
\hline & Incident Power & 0.01 & W \\
\hline & Radiation Efficiency & 0.9292 & \\
\hline & Front to Back Ratio & 598.42 & \\
\hline & Decay Factor & 0 & \\
\hline
\end{tabular}

\section{CONCLUSION}

The parasitic stack coupled to the driven elements provides the combined benefits of horizontal and vertical parasitic coupling. Result of the study indicate that the number of elements in the parasitic stack has a significant influence on the number of bands the antenna operates, gain, directivity and inter-band separation that is very critical to mitigate the adjacent band interference. For single parasitic element placed symmetrical to driven element, the antenna array operates at three different bands. The first band is at $6.1 \mathrm{Ghz}$ with bandwidth of $250 \mathrm{Mhz}$ that supports mobile wireless and fixed satellite service,the second band is at 7.1Ghz with bandwidth of $350 \mathrm{Ghz}$ that supports mobile wireless, fixed wireless and fixed satellite service. The third band is $11.6 \mathrm{Ghz}$ with bandwidth of $1.4 \mathrm{Ghz}$ that supports fixed wireless and fixed satellite services. For a parasitic stack of two elements, the array still operates at triple band, but for the third band at $11.6 \mathrm{GHz}$, the impedance bandwidth improved to $1.5 \mathrm{GHz}$, from $1.4 \mathrm{Ghz}$ for single parasitic element placed symmetrical to driven element, an improvement of $1000 \mathrm{Mhz}$ bandwidth. For three parasitic element stack, the operating bands are reduced to two, from the earlier three bands in two elements parasitic stack. The first band is at $6 \mathrm{GHz}$ with an impedance bandwidth of $300 \mathrm{MHz}$, and the second band is at $11.6 \mathrm{GHz}$ with an impedance bandwidth of $1.7 \mathrm{GHz}$. A significant observation from the study is that, in the three element parasitic stack, the inter-band separation is very significant of the order of $11.6 \mathrm{Ghz}-6 \mathrm{Ghz}=5$. 6Ghz. This help mitigate the adjacent band interference.

For a single parasitic element coupled to driven element, the gain is $7.46 \mathrm{~dB}$, and it increased to $7.82 \mathrm{~dB}$ for two element parasitic stack, and to 8.38 for three element stack. The directivity of single parasitic element coupled symmetrically to driven element is $7.97 \mathrm{~dB}$, and it increased to $8.42 \mathrm{~dB}$ for two element stack, and ultimately to $9.02 \mathrm{~dB}$ for three element parasitic stack. This has an advantage over conventional array that use more active antenna elements that are geometrically displaced, that have the limitation of more power consumption and more space occupancy. 


\section{ACKNOWLEDGEMENTS}

The authors would like to acknowledge the Ethiopian Institute of Technology, Mekelle University, Mekelle, Ethiopia, for facilitating to carry out the work.

\section{REFERENCES}

[1] A.F.A. Ayoub, “Analysis of Rectangular Microstrip Antennas with Air Substrate," Journal of Electromagnetic Waves and Applications, vol. 17, no. 12, pp. 1755-1766, 2012.

[2] M. Gupta et al., "Rectangular Microstrip Patch using air as Substrate for S-Band Application," Journal of Electromagnetic Analysis and Applications, vol. 6, no. 3, pp. 38-42, 2014.

[3] M.A. Layegh et al., "The Optimization Design of a Novel Slotted Microstrip Patch Antenna with Multibands Using Adaptive Network-based Fuzzy Inference System, Technologies, vol. 5, no. 4, pp. 75, 2017.

[4] J. Saini and S.K. Agarwal, "T and L Slotted Patch Antenna for Future Mobile and Wireless Communication Computing, $8^{\text {th }}$ International conference on Communication and Network Technologies(ICCCNT), New Delhi, India, 2017.

[5] D. Fitsum et al., "Dualband Proximity Coupled Feed Microstrip Patch Antena with T-slot on the Radiating Patch and Dumbbell Shaped Defected Ground Structure," Indonesian Journal of Electrical Engineering and Computer Science (IJEECS), vol. 3, no. 2, pp. 435-440, 2016.

[6] G. Zhou, "Shorting Pin Loaded Annular Ring Microstrip antenna," Antenna and Propagation Society International Symposium, IEEE. Illinois, USA, 1998.

[7] P. Singh, "Rectangular Notch Loaded Dualband Annular Ring Patch Antenna," Journal of Microwave, Optoelectronics and Electromagnetic Application, vol. 13, no. 1, 2014.

[8] Khanna et al., "Bandwidth enhnacement of modified square fractal microstrip patch antenna using gap-coupling," Engineering Science and Technology, an International Journal, vol. 18, no. 2, pp. 286-293, 2015.

[9] D.K. Srivastava et al., "Design of Wideband gap-coupled modified square fractal antenna, "Journal of Computational Electronics," vol. 15, no. 1, 2016.

[10] M.K. Verma et al., "A Novel Circularly Polarized gap-coupled Wideband Antenna with DGS for X/Ku Applications, Electromagnetics, vol. 39, no, 3, 2019.

[11] K. Peng et al., "Bandwidth Enhancement L-Shaped Patch Antenna with Parasitic Element for 5.8Ghz Wireless Local Area Network Applications," Wireless Personal Communications, vol. 9, no. 3, pp. 1163-1170, 2016.

[12] C.K..Wu and K.L. Wong, "Broadband Microstrip Antenna with Directly Coupled Parasitic Patches," Microwave Optical Technology Letters, vol. 22, pp. 348-349, 1985.

[13] V. Sharma and R.K. Viswakarma, "A Stacked Microstrip antenna for multiband operation," 2015 International Conference on Computer, Communication and Control(IC4), India, 2016.

[14] Agarwal and A. Kaur, "A Dualband Stacked Aperture Coupled Antenna for WLAN Applications," Microwave and Optical Technology Letters, vol. 59, no. 3, 2017.

[15] J. Padhi et al., "Design of a Stacked Two Layer Circular Fractal Microstrip Antenna for X-band Application. 2016 IEEE Annual India Conference(INDICON), India, 2016.

[16] S. Kumar et al., "Miniaturized Inverted Multiband Stacked Triangular Fractal Patch Antenna for Wireless Communication," 2014 International Conference on Signal Processing and Integrated Networks(SPIN). India, pp. 2-11, 2016.

[17] X.Ren et al., "A Stacked Microstrip Antenna Array with Fractal Patches, "International Journal of Antenna and Propagation, vol. 2014, pp. 1-10, 2014.

[18] J. Anguera, "Dual Frequency Broadband Microstrip Antenna with a Reactive Loading and Stacked Elements, "Progress in Electromagnetics Research Letters, vol. 10, pp. 1-10, 2009.

[19] K.P. Ray et al., "Compact Broadband Gap-coupled Rectangular Microstrip Antenna," Microwave and Optical Technology Letters, vol. 48, no. 12, pp.2384-2389, 2006.

[20] R. Ritu et al., "Bandwidth Enhancement Using Gap-coupled Hexagonal Microstrip Antenna in L-band," Microwave and Optical Technology Letters, vol. 55, no. 11, pp. 2703-2709, 2016.

[21] K.F. Lee et al., Microstrip Patch Antennas, $2^{\text {nd }}$ Edition, World Scientific Publishing Co. Pte. Ltd, Singapore.

[22] J.P. Gianvittorio and Y.R. Sami, "Fractal Antennas: A Novel Antenna Miniaturization Technique, and Applications," IEEE Antennas Propagation Magazine, vol. 44, no. 1, pp. 20-36, 2002.

[23] D. Mitra et al., "A miniaturized Ring Slot Antenna with Enhanced Radiation Characteristics," IEEE Transaction on Antenna and Propagation, vol. 64, no. 1, pp. 300-305.

[24] H. Oraizi and Y. Hedayati, "Miniaturization of Microstrip Antennas by the Novel Application of the Giuseppe Peano Fractal Geometries," IEEE Transaction an Antenna and Propagation, vol. 60, no. 8, pp. 3559-3567, 2012.

[25] S.R. Best, "A Discussion on the Significance of Geometry in Determining the Resonant Behavior of Fractal and Others," IEEE Antennas Propagation Magazine, vol. 45, no. 3, 2003.

[26] M.F. Barnsley, Fractals Everywhere, $2^{\text {nd }}$ edition, Academic press, 1993, U.S.A.

[27] P. Heinz-Otto et al., Chaos and Fractals: New Frontiers of Science, $2^{\text {nd }}$ Edition, Springer, 2004.

[28] S.T. Yadav and M. AkhilesH, "Ultra-wideband Antenna Using Minkowski- Like Fractal Geometry," Microwave and Optical Technology Letters, vol. 56, no. 10, pp. 4130-4136, 2014.

[29] T.S. Bird, "Definition and Misuse of Return Loss," IEEE Antennas and Propagation Magazine, vol. 51, no. 2, pp. 166-167, 2009. 